\title{
Effects of various methods of dexmedetomidine administration for sedation in elderly patients undergoing spinal anesthesia: a randomized controlled study
}

\author{
Jeong Jeong, So Hee Jin, Dong Yeon Kim, Sooyoung Cho, \\ Heeseung Lee, and Jong In Han
}

Received January 25, 2020

Revised April 18, 2020

Accepted April 22, 2020

Department of Anesthesiology and Pain Medicine, Ewha Womans University Mokdong Hospital, Ewha Womans University College of Medicine, Seoul, Korea

\author{
Corresponding author \\ Dong Yeon Kim, M.D., Ph.D. \\ Department of Anesthesiology and \\ Pain Medicine, Ewha Womans \\ University Mokdong Hospital, Ewha \\ Womans University College of \\ Medicine, 1071 Anyangcheon-ro, \\ Yangcheon-gu, Seoul 07985, Korea \\ Tel: 82-2-2650-5285 \\ Fax: 82-2-2655-2924 \\ E-mail: kdyeon@ewha.ac.kr
}

Background: The purpose of this study was to investigate the degree of sedation and the incidence of adverse effects resulting from various methods of administering the initial dose followed by continuous infusion of dexmedetomidine (DEX) for sedation in elderly patients undergoing spinal anesthesia.

Methods: In total, 72 patients aged over 65 years who were to be administered spinal anesthesia were randomly allocated into three groups. The initial doses were injected to the groups as follows: group DD, DEX $0.5 \mu \mathrm{g} / \mathrm{kg}$ for $10 \mathrm{~min}$; group MD, midazolam $0.02 \mathrm{mg} / \mathrm{kg}$; and group D, no initial dose. This was followed immediately by infusing a maintenance dose of DEX $0.5 \mu \mathrm{g} / \mathrm{kg} / \mathrm{h}$ to all groups.

Results: The Bispectral index (BIS) in the D group was significantly higher than in the other two groups. There were no significant differences in the Ramsay sedation scale (RSS) among the groups. The RSS 3 level was reached in 10 min from the start of sedation in MD and DD groups and in 20 min from the start of sedation in D group. Neither bradycardia nor hypotension was observed in any of the groups.

Conclusions: Patients in all three groups reached the RSS 3 sedating-effect level. However, the group that received continuous infusion only without the initial dose showed higher BIS than the other two groups and reached the RSS 3 later. No adverse events were observed in any of the groups.

Keywords: Dexmedetomidine; Elderly; Midazolam; Spinal anesthesia.

\section{INTRODUCTION}

With advancements in medical sciences and the improved quality of life in recent years, the elderly population is consistently increasing. As a result, the number of surgeries performed on elderly patients is also rising; spinal anesthesia is the usual choice for urologic or lower-extremity surgeries. Appropriate sedation during spinal anesthesia relieves patient's anxiety and induces loss of harmful memories.

Dexmedetomidine (DEX) is a selective $\alpha_{2}$-adrenergic agonist that triggers sedative effects by acting on the locus ceruleus, and it has been used more commonly in recent

This is an Open Access article distributed under the terms of the Creative Commons Attribution Non-Commercial License (http://creativecommons.org/licenses/by-nc/4.0) which permits unrestricted non-commercial use, distribution, and reproduction in any medium, provided the original work is properly cited.

Copyright (c) the Korean Society of Anesthesiologists, 2020 
years. Some benefits of this agent include easy transition from a sedated state to an alert state that facilitates patient's cooperation during surgery, cardiovascular stability with little respiratory depression, and a lower incidence of delirium in elderly patients [1,2].

Regional anesthesia is beneficial since the patient remains conscious and breathes spontaneously, with normal reflexes such as coughing being preserved. Although sedation is commonly induced during regional anesthesia, it is important to ensure that the patient's consciousness is minimally diminished with no suppression of reflexes and respiration. Monitoring of the level of sedation is crucial to attain an appropriate sedation; the Bispectral index (BIS) is widely used for this purpose. The BIS enables a quantitative monitoring of the level of sedation and hypnosis on a scale from 0 to 100 . The score of $70-90$ indicates mild, and the score of 60-69 indicates moderate sedation [3].

Aging decreases tissue elasticity that lowers electrical conduction in the heart and decreases response to receptor stimulation. The diminished vascular elasticity increases the risk of hypertension, ventricular hypertrophy, and heart failure [4]. Moreover, progression of aging disrupts ventilation and perfusion balance that increases the vulnerability to hypoxia and provokes the sensitive responses to respiratory depressants. Compared to younger patients, older adults' brains are more sensitive to anesthetics and are susceptible to unwanted hemodynamic variations [5]. For this reason, selection of a proper sedative and the method of administration during regional anesthesia in elderly patients have become an important issue for anesthesiologists. In recent years, DEX has been preferred as the sedative for regional anesthesia in elderly patients but the effective concentration of this agent for inducing sedation in elderly patients is yet unknown. Occurrence of severe bradycardia triggered by excessive initial dose has been reported [6].

The purpose of this study was to investigate the degree of sedation and the incidence of adverse effects resulting from various methods of administering the initial dose followed by continuous infusion of DEX for sedation in elderly patients undergoing spinal anesthesia.

\section{MATERIALS AND METHODS}

This study was approved by the institutional-review board of the authors' affiliation (no. 2018-07-103), and a written informed consent was obtained from all patients. The study patients were aged 65 years or older and Ameri- can Society of Anesthesiologists physical status classification I-II, and were scheduled to undergo a closed peritoneal surgery at perineal region under spinal anesthesia. Patients with relative or absolute contra indications for spinal anesthesia, including those with coagulopathy, skin infection, severe low back pain, or history of spinal surgery, were excluded. Seventy-two patients were randomized to three groups of 24 patients each. The author in charge of patient randomization used computer-generated random numbers with Microsoft Excel that were used to assign patients to study groups; he ensured that the patients entered the operating room as randomized, administered the intervention, and supervised the overall process.

Upon arrival at the operating room, patient's vital signs were monitored using electrocardiography, non-invasive blood pressure, and pulse oximetry. To monitor sedation, BIS (BIS ${ }^{\mathrm{TM}}$ Vista A-3000 monitor, Software version 3.20, Aspect Medical Systems, Inc., USA) and Ramsay sedation scale (RSS) scores (Table 1) were checked [7]. All patients were administered $5 \mathrm{ml} / \mathrm{kg}$ of plasma solution A in 1,000 $\mathrm{ml}$ (CJ Cheiljedang, Korea) prior to spinal anesthesia. Spinal anesthesia was performed with the patient in the lateral decubitus position; a 25-gauge Quincke needle was inserted into the L3-4 or 4-5 vertebral interspace to administer $0.5 \%$ bupivacaine (Marcaine ${ }^{\circledR}$ Spinal Heavy $0.5 \%$, AstraZeneca AB, Sweden). The dose of the bupivacaine was determined according to the patient's age and height. The patient was then turned to the supine position, and the level of anesthesia was checked. While supplying oxygen at $2 \mathrm{~L} / \mathrm{min}$ using a nasal cannula (Comfort Soft Plus ${ }^{\circledR} \mathrm{CO}_{2}$ Sampling Nasal Cannula, Westmed Inc., USA), the patient's hemodynamic stability was confirmed. After changing the patient to the lithotomy position, the corresponding sedatives were administered to each patients depending on their group. This time point of administration was defined as T0. Time points at $10 \mathrm{~min}, 20 \mathrm{~min}, 30 \mathrm{~min}$, and $60 \mathrm{~min}$ after the start of administration were defined as T10, T20,

Table 1. Ramsay Sedation Scale [7]

\begin{tabular}{cl}
\hline Score & \multicolumn{1}{c}{ Response } \\
\hline 1 & Patient is anxious and agitated or restless or both \\
2 & Patient is co-operative, oriented, and tranquil \\
3 & Patient responds to commands only \\
4 & Patient exhibits brisk response to light glabellar tap or loud au- \\
& ditory stimulus \\
5 & Patient exhibits a sluggish response to light glabellar tap or \\
& loud auditory stimulus \\
\hline
\end{tabular}


T30, and T60, respectively.

The DD group, DEX (Precedex Premix, $4.72 \mu \mathrm{g} / \mathrm{ml}$, Pfizer Pharmaceuticals Korea, Korea) was given at the initial dose of $0.5 \mu \mathrm{g} / \mathrm{kg}$ over $10 \mathrm{~min}$, followed by continuous infusion of DEX at $0.5 \mu \mathrm{g} / \mathrm{kg} / \mathrm{h}$. The MD group was given midazolam at the initial dose of $0.02 \mathrm{mg} / \mathrm{kg}$, followed by continuous infusion of DEX at $0.5 \mu \mathrm{g} / \mathrm{kg} / \mathrm{h}$. The D group was given a continuous infusion of DEX at $0.5 \mu \mathrm{g} / \mathrm{kg} / \mathrm{h}$ without any initial dose. Blood pressure, heart rate, oxygen saturation, respiratory rate, $\mathrm{BIS}$, RSS, and end-tidal $\mathrm{CO}_{2}\left(\mathrm{ETCO}_{2}\right)$ provided via a nasal cannula were measured at every stated time point after $\mathrm{T} 0$.

During the surgery, awareness was defined as the values of RSS being below 2 or of BIS being above 90. Hypoxia was defined as the oxygen saturation $<90 \%$, bradycardia as the heart rate $<45$ beats/min, and hypotension as the mean arterial pressure $<60 \mathrm{mmHg}$ were monitored. Further, postoperative incidence of nausea, vomiting, delirium, and abnormal violent behaviors and movements were noted and assessed. Hypotension was treated with intravenous infusion of $5 \mathrm{mg}$ ephedrine and bradycardia with $0.5 \mathrm{mg}$ atropine. In case of hypoxia, breathing was assisted by opening the patient's mouth and extending the neck.

Sample size was calculated using the $\mathrm{G}^{*}$ Power program version 3.1.9.2 based on the Cohen's formula. Yoon et al. [8] reported a BIS difference of 11.8 between the DEX with midazolam and DEX groups, with the standard deviation set to 12. The sample size for each group was calculated to be 21 for a two-tailed test at a significance of 0.05 and power of 0.8 . Anticipating a $10 \%$ withdrawal rate, we recruited 24 participants for each group, for a total of 72 patients.

All statistical analyses were conducted using the SPSS software (version 18.0, IBM Co., USA). Data were presented as mean \pm standard deviation or the number of patients. When comparing patients' characteristics between groups, continuous data were analyzed with one-way analysis of variance (ANOVA), and categorical data were analyzed with chi-square test or Fisher's exact test. Variations of measures over time between groups were analyzed with repeated-measures ANOVA. Variations over time within groups were analyzed with repeated-measures ANOVA followed by post-hoc Bonferroni for continuous data. $P$ values $<0.05$ were considered statistically significant.

\section{RESULTS}

A total of 72 patients participated in the study, with 24 in each group (Fig. 1). There were no significant differences in age, sex, height, weight, type of surgery, American Society of Anesthesiologists physical status, and the level of spinal anesthesia among the groups (Table 2).

Although the heart rate and mean arterial pressure tended to decrease during surgery, there were no significant differences among the groups after initial sedation (Fig. 2). Intra-operative bradycardia or hypotension did not occur in any of the groups.

BIS tended to decrease over the duration of surgery, and it significantly differed among the groups at $\mathrm{T} 10$ and T30. At T10, BIS was significantly higher in the D group $(82.0 \pm 7.7)$ than in the DD group (77.7 \pm 5.5$)$ and MD group (76.0 \pm 5.5$)$ $(\mathrm{P}<0.010)$. At $\mathrm{T} 30$, BIS was significantly higher in the $\mathrm{D}$ group (76.6 \pm 9.8$)$ than in the DD group $(71.8 \pm 6.7)$ and $\mathrm{MD}$ group $(72.1 \pm 7.1)(\mathrm{P}<0.023)$ (Fig. 3$)$. There were no significant differences in RSS among the groups (Table 3). The DD and MD groups reached the RSS 3 at T10, whereas the D group reached the RSS 3 at T20.

There were no significant differences in oxygen saturation and $\mathrm{ETCO}_{2}$ among the groups (Fig. 4). Respiratory rate did not significantly differ between the groups (Fig. 4). Hypoxia was not observed during surgery in any of the groups. Nausea, vomiting, delirium, and abnormal violent behaviors or movement also did not occur during or after surgery in any of the groups.

\section{DISCUSSION}

This study compared the level of sedation achieved by continuous infusion of a usual dose of DEX in elderly patients undergoing spinal anesthesia, depending on whether a) a initial dose equivalent to the half of the usual dose is used prior to continuous infusion, $b$ ) midazolam is used as the initial dose, and c) continuous infusion is begun immediately without a initial dose. All three methods led to sedation equivalent to the RSS 3 . However, the BIS was higher and took longer time to achieve RSS 3 in the continuous infusion without the initial dose group compared to the other two groups. Adverse events were not observed in any of the three groups.

DEX is a selective $\alpha_{2}$-adrenergic agonist that acts on the $\alpha_{2 \mathrm{~A}}$ and $\alpha_{2 \mathrm{~B}}$ subtypes. $\alpha_{2 \mathrm{~A}}$ receptors are mainly distributed in the periphery, and they reduce norepinephrine secretion in the synaptic terminal and decrease sympathetic nervous activity. DEX induces sedative and analgesic effects by acting on $\alpha_{2 \mathrm{~B}}$ receptors present in the locus ceruleus and spi- 


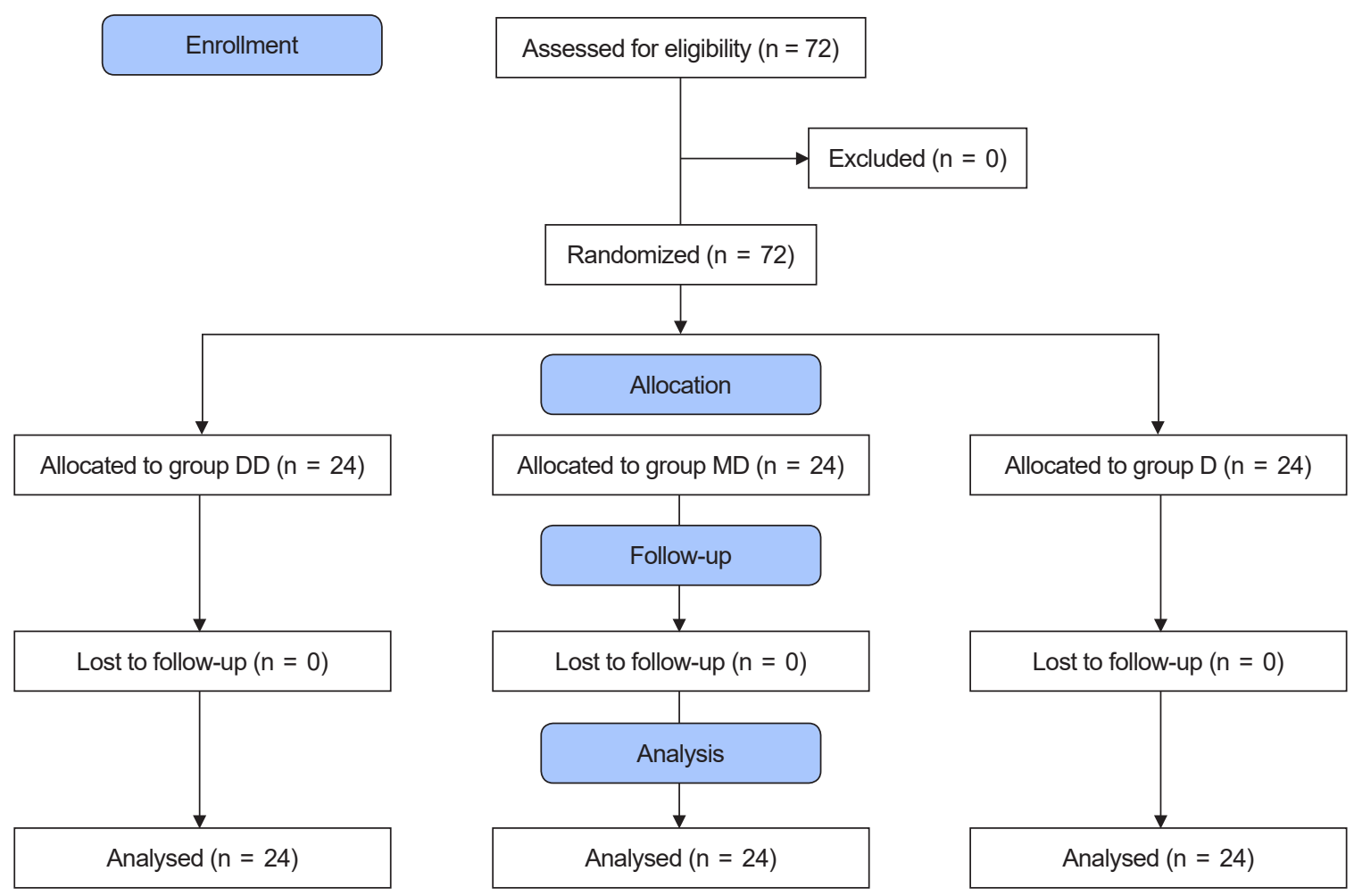

Fig. 1. Consolidated standards of reporting trials (CONSORT) flow chart of the study. A total of 72 patients (American Society of Anesthesiologists physical status classification I-II, aged over 65 years) were randomly allocated into three groups. Group DD: initial dose of $0.5 \mu \mathrm{g} / \mathrm{kg}$ dexmedetomidine + continuous infusion of $0.5 \mu \mathrm{g} / \mathrm{kg} / \mathrm{h}$ dexmedetomidine. Group MD: initial dose of $0.02 \mathrm{mg} / \mathrm{kg}$ midazolam + continuous infusion of $0.5 \mu \mathrm{g} / \mathrm{kg} / \mathrm{h}$ dexmedetomidine. Group D: continuous infusion of $0.5 \mu \mathrm{g} / \mathrm{kg} / \mathrm{h}$ dexmedetomidine without initial dose.

Table 2. Patient's Characteristics

\begin{tabular}{lcccc}
\hline \multicolumn{1}{c}{ Variable } & Group DD $(\mathrm{n}=24)$ & Group MD $(\mathrm{n}=24)$ & Group D $(\mathrm{n}=24)$ & P value \\
\hline Age $(\mathrm{yr})$ & $77.2 \pm 8.1$ & $74.5 \pm 7.3$ & $73.6 \pm 7.1$ & 0.231 \\
Sex (M/F) & $23 / 1$ & $23 / 1$ & $65.4 \pm 10.7$ & 0.080 \\
Weight (kg) & $64.9 \pm 10.8$ & $68.3 \pm 6.06$ & $166.9 \pm 7.6$ & 0.392 \\
Height (cm) & $167.3 \pm 6.0$ & $168.7 \pm 5.4$ & $9.9 \pm 0.5$ & 0.361 \\
Level of spinal anesthesia & $10.2 \pm 0.7$ & $10.4 \pm 0.8$ & $18 / 6$ & 0.063 \\
Operation (TURP/TURB) & $20 / 4$ & $21 / 3$ & $5 / 19$ & 0.701 \\
ASA physical status (I/II) & $3 / 21$ & $8 / 16$ & 0.211 \\
\hline
\end{tabular}

Values are presented as mean $\pm \mathrm{SD}$ or the number of patients. Levels of spinal anesthesia are presented as $\mathrm{T} 8=8, \mathrm{~L} 2=12+2, \mathrm{~L} 4=12+4$. ASA: American Society of Anesthesiologists, TURP: transurethral resection of prostate, TURB: transurethral resection of bladder. Group DD: initial dose of $0.5 \mu \mathrm{g} / \mathrm{kg}$ dexmedetomidine + continuous infusion of $0.5 \mu \mathrm{g} / \mathrm{kg} / \mathrm{h}$ dexmedetomidine. Group MD: initial dose of $0.02 \mathrm{mg} / \mathrm{kg}$ midazolam + continuous infusion of $0.5 \mu \mathrm{g} / \mathrm{kg} / \mathrm{h}$ dexmedetomidine. Group D: continuous infusion of $0.5 \mu \mathrm{g} / \mathrm{kg} / \mathrm{h}$ dexmedetomidine without initial dose. There were no significant differences among the groups.

nal cord, while acting on $\alpha_{2 B}$ receptors present in peripheral-blood vessels induces vasoconstriction. Therefore, vasoconstriction and bradycardia can commonly occur early after infusion of this drug, and hypotension can easily develop once sympathetic nervous activity is suppressed $[9,10]$. The clinical using dose of DEX for sedation is known to consist of a initial dose of $1.0 \mu \mathrm{g} / \mathrm{kg}$ over $10 \mathrm{~min}$ followed by a maintenance dose of $0.4-0.7 \mu \mathrm{g} / \mathrm{kg} / \mathrm{h}$ by continuous infusion [11].
Riker et al. [12] reported that after infusing DEX (0.2-1.4 $\mu \mathrm{g} / \mathrm{kg} / \mathrm{h})$ or midazolam $(0.02-0.10 \mathrm{mg} / \mathrm{kg} / \mathrm{h})$ for sedation in patients receiving mechanical ventilation via endotracheal intubation, the incidence of delirium, tachycardia, and hypertension was lower but that of bradycardia was higher in the DEX group than in the midazolam group. In another study that compared a group of patients receiving a initial dose of $0.05 \mathrm{mg} / \mathrm{kg}$ of midazolam and a group of patients receiving $1 \mu \mathrm{g} / \mathrm{kg}$ of DEX over $10 \mathrm{~min}$ for surgery 

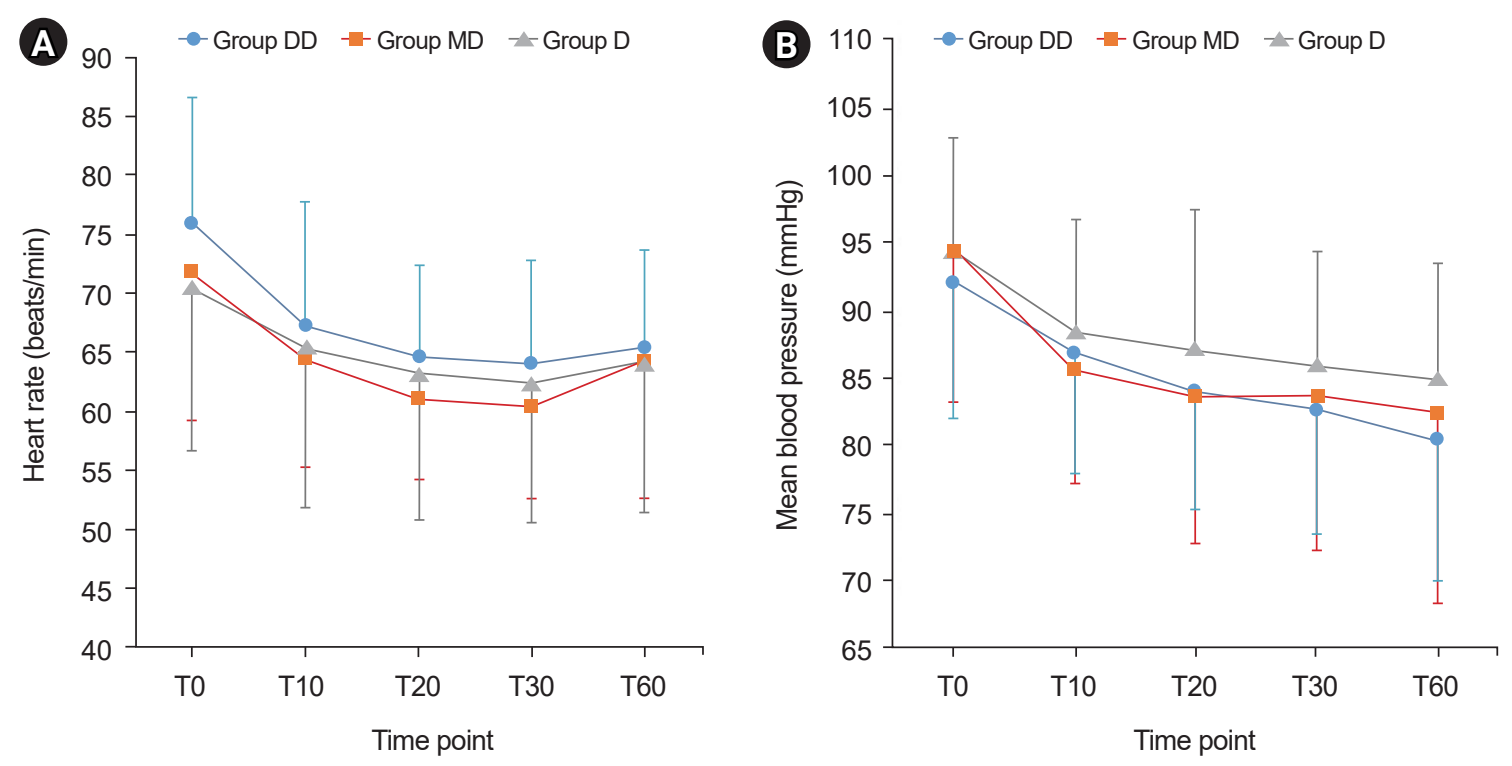

Fig. 2. Trends of heart rate (A) and mean blood pressure (B). Graphs' values are presented as mean \pm SD. Group DD: initial dose of $0.5 \mu g / k g$ dexmedetomidine + continuous infusion of $0.5 \mu \mathrm{g} / \mathrm{kg} / \mathrm{h}$ dexmedetomidine. Group MD: initial dose of $0.02 \mathrm{mg} / \mathrm{kg}$ midazolam + continuous infusion of $0.5 \mu \mathrm{g} / \mathrm{kg} / \mathrm{h}$ dexmedetomidine. Group D: continuous infusion of $0.5 \mu \mathrm{g} / \mathrm{kg} / \mathrm{h}$ dexmedetomidine without initial dose. T0: start sedation, T10, 20, 30, 60: 10, 20, 30, 60 min after sedation. There were no significant differences among the groups at any time point.

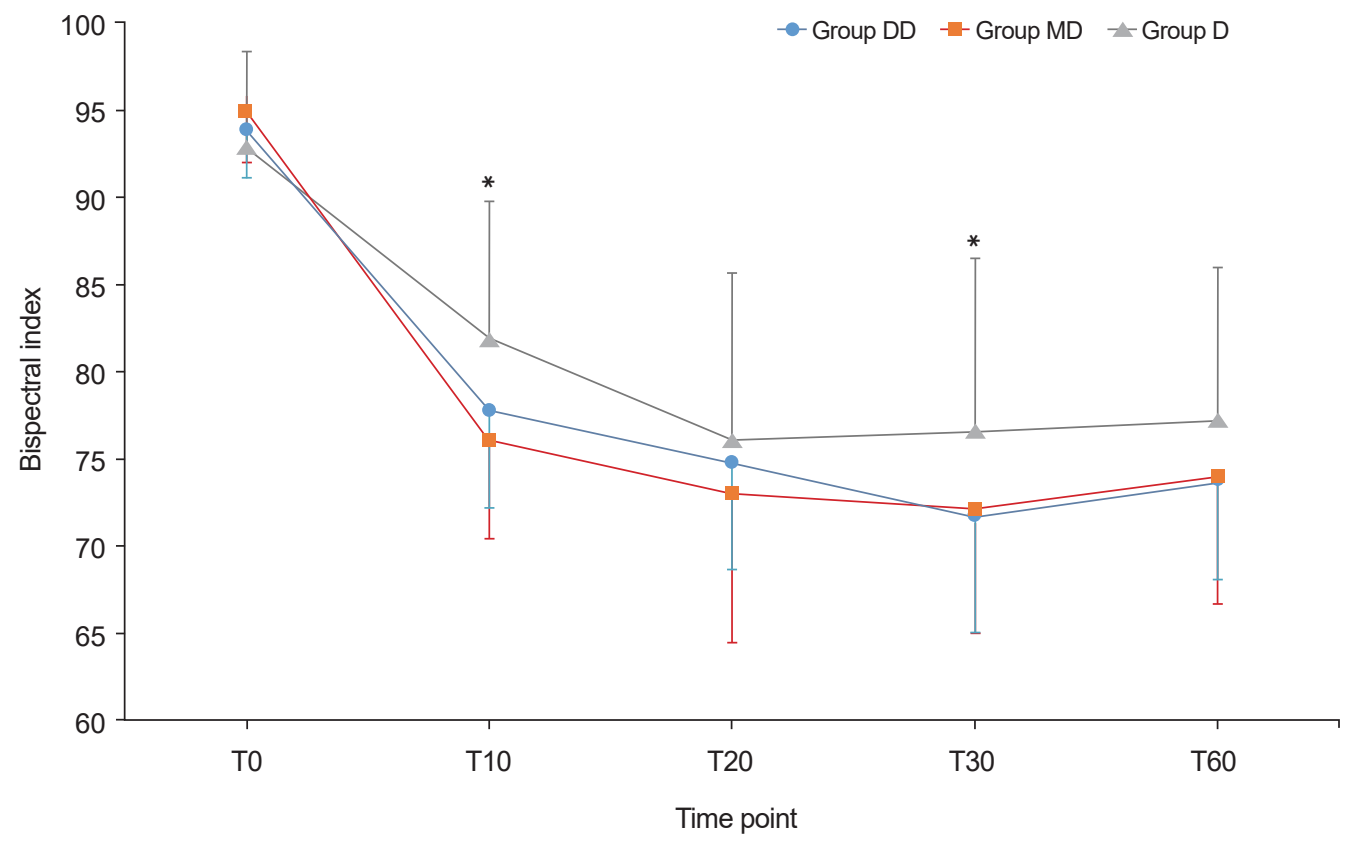

Fig. 3. Trends of Bispectral index. Graphs' values are presented as mean \pm SD. Group DD: initial dose of $0.5 \mu \mathrm{g} / \mathrm{kg}$ dexmedetomidine + continuous infusion of $0.5 \mu \mathrm{g} / \mathrm{kg} / \mathrm{h}$ dexmedetomidine. Group MD: initial dose of $0.02 \mathrm{mg} / \mathrm{kg}$ midazolam + continuous infusion of $0.5 \mu \mathrm{g} / \mathrm{kg} / \mathrm{h}$ dexmedetomidine. Group D: continuous infusion of $0.5 \mu \mathrm{g} / \mathrm{kg} / \mathrm{h}$ dexmedetomidine without initial dose. T0: start sedation, T10, 20, 30, 60: 10, 20, 30 , and 60 min after sedation. Bispectral index in Group D was significantly higher than in the other two groups at T10 and T30. *P $<0.05$. 
Table 3. Ramsay Sedation Scale

\begin{tabular}{lcccc}
\hline Time point & Group DD $(\mathrm{n}=24)$ & Group MD $(\mathrm{n}=24)$ & Group D $(\mathrm{n}=24)$ & P value \\
\hline T0 & $1(1,1)$ & $1(1,1)$ & $1(1,1)$ & 0.281 \\
T10 & $3(3,3)$ & $3(3,3)$ & $2.5(2,3)$ & 0.051 \\
T20 & $3(3,3)$ & $3(3,3)$ & $3(3,3)$ & 0.568 \\
T30 & $3(3,3)$ & $3(3,3)$ & $3(3,3)$ & 0.571 \\
T60 & $3(3,3)$ & $3(3,3)$ & $3(3,3)$ & 0.358 \\
\hline
\end{tabular}

Values are presented as median (1Q, 3Q). Group DD: initial dose of $0.5 \mu g / k g$ dexmedetomidine + continuous infusion of $0.5 \mu g / k g / h$ dexmedetomidine. Group MD: initial dose of $0.02 \mathrm{mg} / \mathrm{kg}$ midazolam + continuous infusion of $0.5 \mu \mathrm{g} / \mathrm{kg} / \mathrm{h}$ dexmedetomidine. Group D: continuous infusion of $0.5 \mu \mathrm{g} / \mathrm{kg} / \mathrm{h}$ dexmedetomidine without initial dose. T0: start sedation, T10, 20, 30, 60: 10, 20, 30, 60 min after sedation. There were no significant differences among the groups.
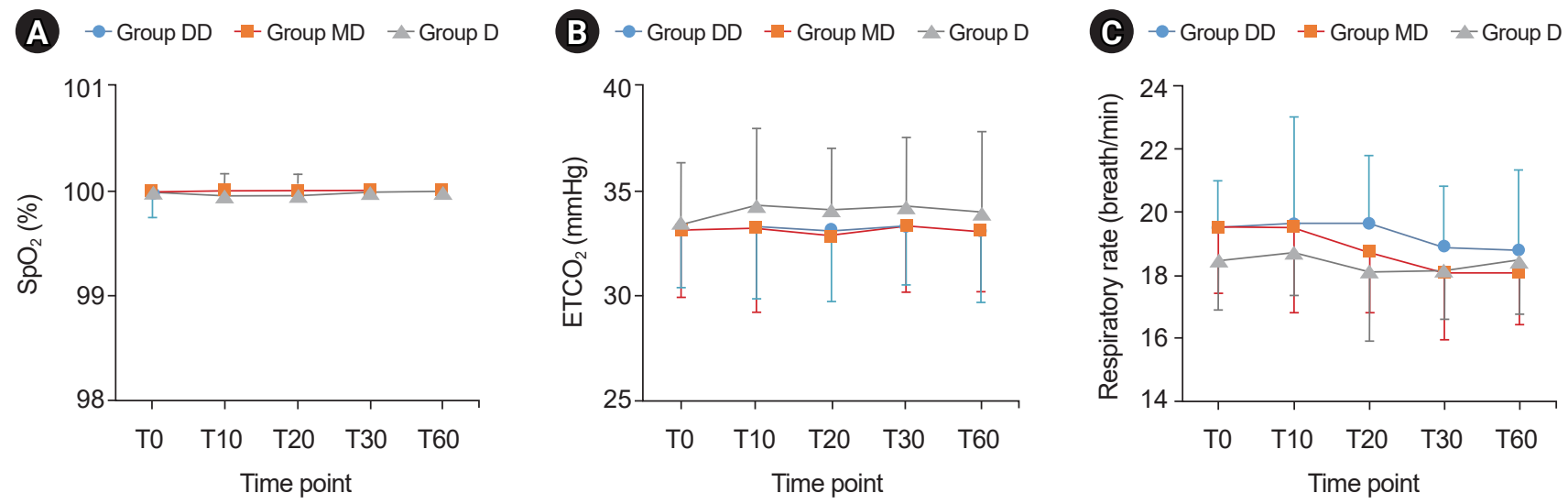

Fig. 4. Trends of oxygen saturation $\left(\mathrm{SpO}_{2}\right)(\mathrm{A})$, end-tidal carbon dioxide $\left(\mathrm{ETCO}_{2}\right)(\mathrm{B})$, and respiratory rate $(\mathrm{C})$. Graphs' values are presented as mean \pm SD. Group DD: initial dose of $0.5 \mu \mathrm{g} / \mathrm{kg}$ dexmedetomidine + continuous infusion of $0.5 \mu \mathrm{g} / \mathrm{kg} / \mathrm{h}$ dexmedetomidine. Group MD: initial dose of 0.02 $\mathrm{mg} / \mathrm{kg}$ midazolam + continuous infusion of $0.5 \mu \mathrm{g} / \mathrm{kg} / \mathrm{h}$ dexmedetomidine. Group D: continuous infusion of $0.5 \mu \mathrm{g} / \mathrm{kg} / \mathrm{h}$ dexmedetomidine without initial dose. T0: start sedation, T10, 20, 30, 60: 10, 20, 30, and 60 min after sedation. There were no significant differences among the groups at any time point.

under spinal anesthesia demonstrated that the DEX group showed a significantly lower heart rate and the midazolam group showed a significantly lower mean arterial pressure [8]. These results suggest that hemodynamic instability is a major issue when using sedatives during spinal anesthesia in elderly patients, who commonly suffer from cardiovascular comorbidities [5].

Yeom et al. [13] investigated the appropriate dose of DEX by comparing three groups: a initial dose of $1.0 \mu \mathrm{g} / \mathrm{kg}$ (based on actual body weight), $1.0 \mu \mathrm{g} / \mathrm{kg}$ (based on ideal body weight), or $0.8 \mu \mathrm{g} / \mathrm{kg}$ (based on ideal body weight) followed by continuous infusion of $0.5 \mu \mathrm{g} / \mathrm{kg} / \mathrm{h}$ (based on each corresponding body weight criterion). They observed that an appropriate level of sedation was maintained in the $0.8 \mu \mathrm{g} / \mathrm{kg}$ (based on ideal body weight) group, and although the incidence of airway obstruction and bradycardia did not significantly differ between the three groups, a total of eight patients developed bradycardia. Another recent study administered DEX at a initial dose of $1 \mu \mathrm{g} / \mathrm{kg}$ over $10 \mathrm{~min}$ (based on the actual or ideal body weight) fol- lowed by a maintenance dose of $0.5 \mu \mathrm{g} / \mathrm{kg} / \mathrm{h}$ in patients (average age, 40 years) who were undergoing surgery under spinal anesthesia. They observed that airway obstruction or coughing and the mean BIS at 30-50 min after sedation were lower than the target of 60-80; they reported that the initial dose and maintenance dose of DEX induced excessive sedation and airway obstruction [14]. Therefore, with reference to a report that a dose of $1 \mu \mathrm{g} / \mathrm{kg}$ induced adverse events in general patients and to ensure safety, we lowered the initial dose of DEX in patients aged 65 years or older to $0.5 \mu \mathrm{g} / \mathrm{kg}$ that is equal to the maintenance dose.

DEX generates appropriate sedative effects without respiratory depression if used within the therapeutic dose [15]. On the other hand, midazolam may induce hypoxia and airway obstruction by reducing respiratory response even in healthy adults [16]. In general, $0.05 \mathrm{mg} / \mathrm{kg}$ of midazolam is used for sedation in adults [17]. Yano et al. [18] used midazolam for sedation during a colonoscopy procedure, specifically a dose of $0.05 \mathrm{mg} / \mathrm{kg}$ for patients under the age of 60 and $0.025 \mathrm{mg} / \mathrm{kg}$ for patients aged 60 years or 
older. When the two groups were compared, the 60 years or older group showed more frequently an oxygen saturation below 95\% despite being administered the lower dose. Therefore, considering that our patients were more than 65 -years old, we used the dose of midazolam reduced to $0.02 \mathrm{mg} / \mathrm{kg}$ for the safety reason. Another study reported that a cumulative midazolam dose of $7 \mathrm{mg}$ or higher in adults aged 65 years or older led to abnormal behaviors such as delirium, violent behaviors, and abnormal movement in about $10.2 \%$ of the patients [19]. In the present study, respiratory depression was not observed during surgery, and oxygen saturation of $95-100 \%$ and $\mathrm{ETCO}_{2}$ of $26-$ $38 \mathrm{mmHg}$ were maintained in all three groups. Further, abnormal behaviors did not occur; we presumed that this is because additional midazolam was not administered beyond the initial dose and that a lower dose of $0.02 \mathrm{mg} / \mathrm{kg}$ than the clinical sedation dose was used in consideration of the old age of the patients.

As elderly patients were enrolled in this study, we compared three groups with a lower initial dose of $0.5 \mu \mathrm{g} / \mathrm{kg}$ DEX, no initial dose of DEX, and lower initial dose of 0.02 $\mathrm{mg} / \mathrm{kg}$ midazolam followed by a maintenance DEX dose of $0.5 \mu \mathrm{g} / \mathrm{kg} / \mathrm{h}$. After the administration of the sedative initial dose, the three groups did not significantly differ in the mean arterial pressure and heart rate and did not show hypotension or bradycardia during surgery. Further, sedation was achieved in all three groups, though the time until sedation varied. The correlation of BIS and RSS has been reported by multiple studies. Bell et al. [20] reported that BIS and RSS are substantially correlated and that a BIS of 87.2 and 80.9 corresponds to RSS 3 and 4, respectively. It has been reported that the appropriate ranges of BIS and RSS for intra-operative sedation are 60-80 and 3-4, respectively [21]. In the present study, BIS was within 50-85 and RSS within 3-4 achieved between 10-60 min after sedation in the two groups that were given a initial dose. However, the group that did not receive a initial dose had a BIS of between 65-90 and RSS of 3, indicating a relatively lower level of sedation; none-the-less, a level of sedation needed to continue the surgery was maintained in all three groups.

Our study involved elderly patients, and by lowering the dose of the agents, we aimed to achieve mild sedation that gives a sense of comfort during surgery without adverse events such as bradycardia, hypotension, and hypoxia. During surgery, all three groups showed a BIS level that indicated mild sedation. Although the continuous infusion only group showed a higher BIS compared to the other two groups, the score only differed by less than 6 points, and the desired sedation was achieved in all three groups without substantial clinical differences.

During the present study, we recorded intra-operative measurements every five minutes after the start of sedation; although hemodynamic instability was not observed, the results were presented in 10-min or 30-min intervals for conciseness. However, as instable vital signs can occur at any point during a surgery, the uncertainty about hemodynamic instability occurring between the indicated time points is one limitation of this study.

In conclusion, we achieved the desired sedative effect in three groups of elderly patients undergoing surgery under spinal anesthesia using a reduced initial dose of DEX or midazolam or only maintenance dose of DEX without a initial dose, with no significant differences in the heart rate and mean arterial pressure among the three groups and no occurrence of bradycardia or hypotension in any of the groups. As the desired level of sedation was achieved and continuously maintained in all three groups, these methods are believed to be hemodynamically safe and appropriate sedation methods for elderly patients.

\section{SUPPLEMENTARY MATERIALS}

Supplementary data containing Korean version of this article is available at https://doi.org/10.17085/apm.20007.

\section{CONFLICTS OF INTEREST}

No potential conflict of interest relevant to this article was reported.

\section{AUTHOR CONTRIBUTIONS}

Conceptualization: Jeong Jeong, Dong Yeon Kim. Data acquisition \& formal analysis: Sooyoung Cho, So Hee Jin. Supervision \& writing—review \& editing: Heeseung Lee, Jong In Han.

\section{ORCID}

Jeong Jeong, https://orcid.org/0000-0003-4894-0344

So Hee Jin, https://orcid.org/0000-0001-9762-2014

Dong Yeon Kim, https://orcid.org/0000-0002-4414-5653

Sooyoung Cho, https://orcid.org/0000-0002-0232-766X

Heeseung Lee, https://orcid.org/0000-0001-7259-466X

Jong In Han, https://orcid.org/0000-0002-8231-7161 


\section{REFERENCES}

1. Jakob SM, Ruokonen E, Grounds RM, Sarapohja T, Garratt C, Pocock SJ, et al. Dexmedetomidine vs midazolam or propofol for sedation during prolonged mechanical ventilation: two randomized controlled trials. JAMA 2012; 307: 1151-60.

2. Fraser GL, Devlin JW, Worby CP, Alhazzani W, Barr J, Dasta JF, et al. Benzodiazepine versus nonbenzodiazepine-based sedation for mechanically ventilated, critically ill adults: a systematic review and meta-analysis of randomized trials. Crit Care Med 2013; 41(9 Suppl 1): S30-8.

3. Sebel PS, Lang E, Rampil IJ, White PF, Cork R, Jopling M, et al. A multicenter study of bispectral electroencephalogram analysis for monitoring anesthetic effect. Anesth Analg 1997; 84: 891-9.

4. Lakatta EG. Arterial and cardiac aging: major shareholders in cardiovascular disease enterprises: Part III: cellular and molecular clues to heart and arterial aging. Circulation 2003; 107: 490-7.

5. Priebe HJ. The aged cardiovascular risk patient. Br J Anaesth 2000; 85: 763-78.

6. Ebert TJ, Hall JE, Barney JA, Uhrich TD, Colinco MD. The effects of increasing plasma concentrations of dexmedetomidine in humans. Anesthesiology 2000; 93: 382-94.

7. Dawson R, von Fintel N, Nairn S. Sedation assessment using the Ramsay scale. Emerg Nurse 2010; 18: 18-20.

8. Yoon DK, Ban JS, Lee SG, Lee JH, Kim E, An J. Dexmedetomidine combined with midazolam vs. dexmedetomidine alone for sedation during spinal anesthesia. Korean J Anesthesiol 2016; 69: 446-52.

9. Kallio A, Scheinin M, Koulu M, Ponkilainen R, Ruskoaho H, Viinamäki $\mathrm{O}$, et al. Effects of dexmedetomidine, a selective alpha 2 -adrenoceptor agonist, on hemodynamic control mechanisms. Clin Pharmacol Ther 1989; 46: 33-42.

10. Paris A, Tonner PH. Dexmedetomidine in anaesthesia. Curr Opin Anaesthesiol 2005; 18: 412-8.

11. Arain SR, Ebert TJ. The efficacy, side effects, and recovery char- acteristics of dexmedetomidine versus propofol when used for intraoperative sedation. Anesth Analg 2002; 95: 461-6.

12. Riker RR, Shehabi Y, Bokesch PM, Ceraso D, Wisemandle W, Koura F, et al. Dexmedetomidine vs midazolam for sedation of critically ill patients: a randomized trial. JAMA 2009; 301: 48999.

13. Yeom JH, Ahn DW, Kim KH. Comparison of several dosing schedules of intravenous dexmedetomidine in elderly patients under spinal anesthesia. Anesth Pain Med 2017; 12: 320-5.

14. Yeom JH, Oh MK, Ahn DW, Park SI. A loading dose of $1 \mu \mathrm{g} / \mathrm{kg}$ and maintenance dose of $0.5 \mu \mathrm{g} / \mathrm{kg} / \mathrm{h}$ of dexmedetomidine for sedation under spinal anesthesia may induce excessive sedation and airway obstruction. Anesth Pain Med 2016; 11: 255-9.

15. Johson JO, Grecu L, Lawson NW. Autonomic nervous system. In: Clinical anesthesia. 6th ed. Edited by Barash PG, Cullen BF, Stoelting RK, Cahalan MK, Stock MC: Philadelphia, Wolters Kluwer/Lippincott Williams \& Wilkins. 2009, pp 326-68.

16. Alexander CM, Gross JB. Sedative doses of midazolam depress hypoxic ventilatory responses in humans. Anesth Analg 1988; 67: 377-82.

17. Nishiyama T, Hirasaki A, Odaka Y, Iwasaki T, Seto K. Midazolam sedation during spinal anesthesia: optimal dosage. J Jpn Soc Clin Anesth 1994; 14: 257-62.

18. Yano H, Iishi H, Tatsuta M, Sakai N, Narahara H, Omori M. Oxygen desaturation during sedation for colonoscopy in elderly patients. Hepatogastroenterology 1998; 45: 2138-41.

19. Liu J, Singh H, White PF. Electroencephalographic bispectral index correlates with intraoperative recall and depth of propofol-induced sedation. Anesth Analg 1997; 84: 185-9.

20. Bell JK, Laasch HU, Wilbraham L, England RE, Morris JA, Martin DF. Bispectral index monitoring for conscious sedation in intervention: better, safer, faster. Clin Radiol 2004; 59: 1106-13.

21. Weinbroum AA, Szold O, Ogorek D, Flaishon R. The midazolam-induced paradox phenomenon is reversible by flumazenil. Epidemiology, patient characteristics and review of the literature. Eur J Anaesthesiol 2001; 18: 789-97. 